\title{
Changing Host Photosynthetic, Carbohydrate, and Energy Metabolisms Play Important Roles in Phytoplasma Infection
}

\author{
Chaoling Xue, Zhiguo Liu, Li Dai, Jiaodi Bu, Mengjun Liu, Zhihui Zhao, Zihui Jiang, Weilin Gao, and Jin Zhao ${ }^{\dagger}$
}

First, fourth, seventh, eighth, and ninth: College of Life Science, Hebei Agricultural University, Baoding, Hebei 071001, China; first, fourth, and ninth authors: Key Laboratory of Hebei Province for Plant Physiology and Molecular Pathology, Hebei Agricultural University, Baoding, Hebei 071001, China; and second, third, fifth, and sixth authors: Research Center of Chinese Jujube, Hebei Agricultural University, Baoding, Hebei 071001, China.

Accepted for publication 10 April 2018.

\begin{abstract}
Phytoplasmas parasitize plant phloem tissue and cause many economically important plant diseases. Jujube witches'-broom disease is a destructive phytoplasma disease of Chinese jujube (Ziziphus jujuba). To elucidate the influence of phytoplasma on host photosynthetic, carbohydrate and energy metabolisms, four types of jujube tissues showing disease symptoms with different severity were investigated at the structural, physiological, and molecular levels. Quantitative real-time PCR and high-performance liquid chromatography results showed that the down-regulation of genes related to photosynthesis and the lower contents of chlorophyll in diseased leaves. This clearly inhibited the light-harvesting and photosystem II activity of photosynthesis; however, overexpression of genes related to starch, sucrose and glucose synthesis

led to higher contents of these carbohydrates. Meanwhile, transmission electron microscopy images revealed that dense amounts of phytoplasmas accumulated in the sieve elements of diseased petiole phloem, and the structure of the grana and stroma lamellae of chloroplasts in the diseased leaves was destroyed. Phytoplasma infection inhibited photosynthesis and led to abnormal carbohydrate accumulation in the diseased leaves. Furthermore, comparative metabolite analysis indicated that phytoplasma infection also stimulated amino acids and energy metabolisms of the diseased leaves. Continually inhibiting the photosynthetic process and stimulating carbohydrate and energy metabolisms of diseased trees may exhaust their nutrients. Our results highlight the importance of changing host metabolisms during the pathogenic process.
\end{abstract}

Phytoplasmas constitute a class of cell wall-free prokaryotic organisms that parasitize plant phloem tissue (Pagliari et al. 2016; Su et al. 2011). Hundreds of plant species, including many economically important crop and fruit trees, can be infected by phytoplasmas (Gurr et al. 2016; Liu et al. 2016; Strauss 2009). Yellowing is a typical symptom of phytoplasma diseases, which indicates that the host plant photosynthesis is significantly affected. Although phytoplasma infection alters chlorophyll (Chl) content, photosynthetic pigments, and the expression levels of genes related to photosynthesis in host plants (Bertamini et al. 2002; Liu et al. 2016; Reinero and Beachy 1989; Sinclair et al. 1997), the structural (at the cellular level), physiological, and molecular mechanisms underlying these changes systematically remain unclear.

The phytoplasma genome lacks genes required to process metabolic energy on their own but contains genes for well-developed sugar transporters for consuming nutrients from host plants (Bai et al. 2006). Phytoplasma infection also interferes with normal carbohydrate metabolism in plants (Maust et al. 2003), although the molecular mechanisms underlying this process remain unknown. In higher plants, a portion of photosynthetic products are converted to starch in the chloroplast, and the other portion is transported to

†Corresponding author: J. Zhao; E-mail: zhaojinbd@126.com

First and second authors contributed equally to this work.

Funding: This study was supported by grants from the Funds for Hebei Distinguished Young Scholar grant number C2016204145 and the Hebei Agricultural University Foundation for Leaders of Disciplines in Science Technology to J. Zhao. The funding agencies had no role in study design, data collection and analysis, decision to publish, or the preparation of the manuscript.

*The $\boldsymbol{e}$-Xtra logo stands for "electronic extra" and indicates that two supplementary figures and six supplementary tables are published online.

(c) 2018 The American Phytopathological Society the cytoplasm for sucrose synthesis and other metabolic processes (Cséke and Buchanan 1986). Because photosynthesis is closely related to carbohydrate and energy metabolism, systematic verification of the phytoplasma influence on these metabolisms of the host plant, especially the effects on the pathogenic process, is very valuable.

Jujube witches'-broom disease (JWB) associated with 'Candidatus Phytoplasma ziziphi' is a typical phytoplasma disease. This disease causes large economic losses and destructive death in the Chinese jujube industry. JWB symptoms include yellowing, small and dense leaves on clustered branches (witches'-broom), phyllody, dense root suckers, and the lack of defoliation during winter. In this study, the effects of phytoplasma on jujube photosynthesis were analyzed by measuring Chl content and fluorescence parameters. To further detect both ultrastructure and histological structure modification in jujube following phytoplasma challenge, we investigated the structure of mesophyll cells and phloem using microscopy. In addition, the contents of starch and the contents of both sucrose and glucose in diseased leaves were also examined using a commercial starch kit and high-performance liquid chromatography (HPLC), respectively. Obtained data combined with transcriptome and metabolome data gave insight about the influence of phytoplasmas on photosynthetic, carbohydrate and energy metabolisms. Our study will provide evidence and new perspectives on the pathogenic process of phytoplasmas.

\section{MATERIALS AND METHODS}

Plant materials. Three healthy jujube trees of Ziziphus jujuba Mill. 'Dongzao' and three trees infected with JWB used in this study were from the Experimental Station of Chinese Jujube, Hebei Agricultural University. Three types of leaf samples showing disease symptoms with different severity and healthy asymptomatic leaves were collected in June, July, August, and September: 
apparently normal leaves (ANL), phyllody leaves (PL), and witches'broom leaves (WL) of the diseased trees as well as healthy leaves (HL) of the healthy trees. All sample types consisted of three biological replicates.

Detection of JWB phytoplasmas. The distribution and concentration of JWB phytoplasmas were determined using 4',6- diamidino-2-phenylindole (DAPI) at histological level (Porter and Feig 1980), transmission electron microscopy (TEM) at the ultrastructural level (Siddique et al. 1998), and quantitative realtime PCR analysis (qRT-PCR) at the molecular level (Yuan 2014). The thymidylate kinase $(T M K)$ gene of phytoplasma (KC493615) was used for phytoplasma diagnosis (Yuan 2014). TMK expression
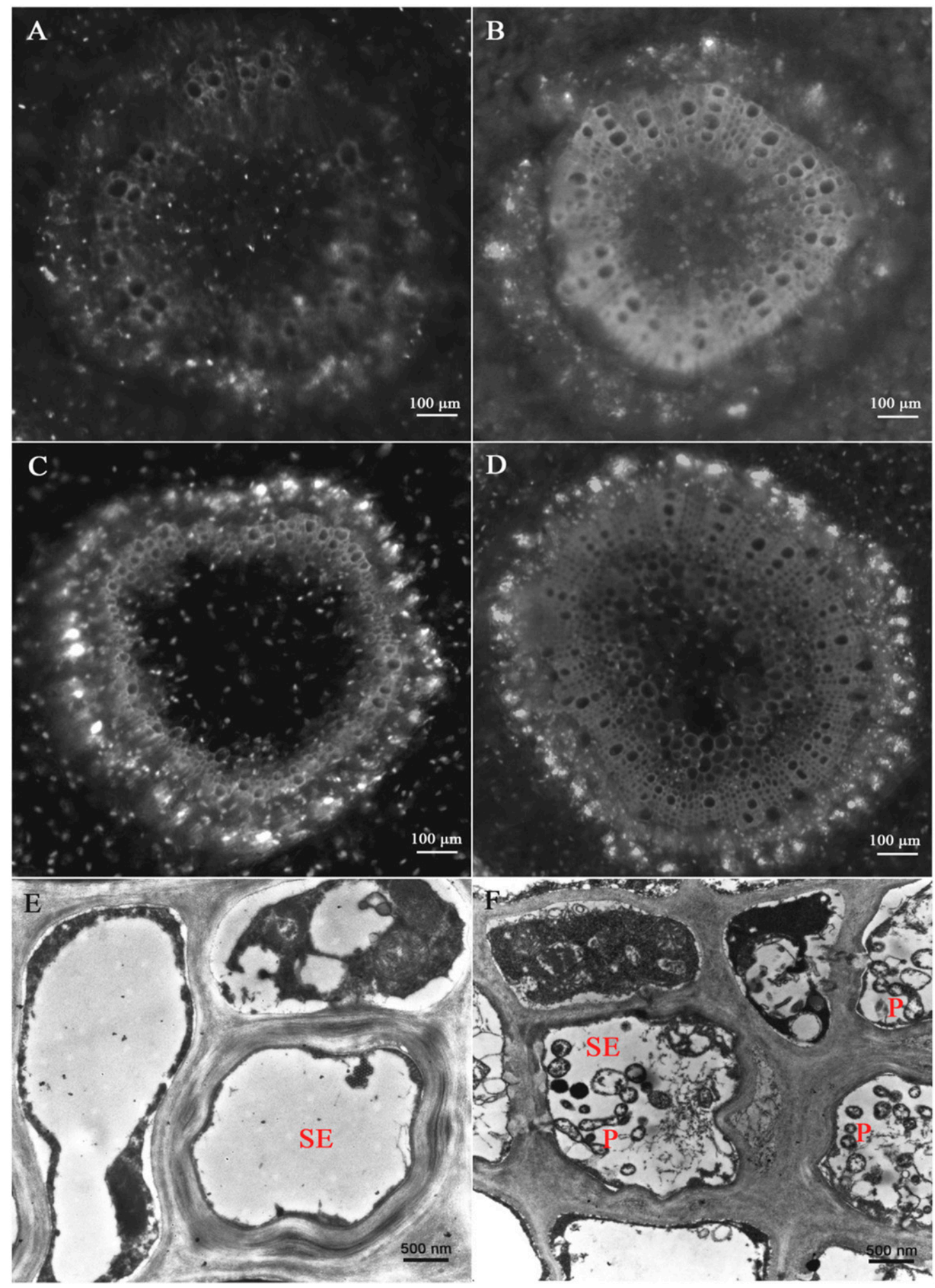

Fig. 1. Phytoplasma determination in jujube stems by using A, B, C, and D, 4', 6 -diamidino-2-phenylindole and $\mathbf{E}$ and $\mathbf{F}$, transmission electron microscopy. A, No fluorescent spots in the sieve element (SE) of healthy stems. Bar $=100 \mu \mathrm{m}$. B, Some fluorescent spots in the SE of the apparently normal stem. The number and size of fluorescent spots represent the number of phytoplasma. Bar $=100 \mu \mathrm{m}$. C, The fluorescent spots formed a large bright circle in the SE of the witches'-broom stem. Bar $=100 \mu \mathrm{m}$. D, The fluorescent spots formed a large bright circle in the SE of the phyllody stem. Bar $=100 \mu \mathrm{m}$. E, No phytoplasmas $(\mathrm{P})$ were presented in the SE of the healthy stem. Bar $=500 \mathrm{~nm}$. F, Phytoplasmas in an SE of the diseased stem. Bar $=500 \mathrm{~nm}$. 
in diseased jujube leaves was analyzed using qRT-PCR in which ZjACT1 served as the internal control. The primers used were as follows: ZjACT (forward primer: 5'-AGCCTTCCTGCCAACG AGT-3', reverse primer: 5'-TTGCTTCTCACCCTTGA TGC-3') (Bu et al. 2016) and $T M K$ (forward primer: 5'-GCAACAAATCC AAGAAGAGGA AA-3', reverse primer: 5'-TTGCGAGGATAA GCTTGATAGG-3').

JWB phytoplasmas in the phloem and chloroplast structures of jujube leaves were observed using TEM (Pagliari et al. 2016). A 1-mm-long midrib portion was excised from each sample of fresh and young leaves. The leaves and stem segments were immediately submerged in $4 \%$ glutaraldehyde overnight at $4{ }^{\circ} \mathrm{C}$ (extraction vacuum for $30 \mathrm{~min}$ ). The samples were rinsed three times every $30 \mathrm{~min}$ in $0.1 \mathrm{M}$ phosphate buffer, after which they were immersed in a $0.1 \%$ osmium tetroxide fixation solution for $2.5 \mathrm{~h}$. The samples were again rinsed for $30 \mathrm{~min}$ twice in the same buffer. Then, the samples were dehydrated in a graded acetone series and embedded in Epon. Ultrathin sections (60- to 70-nm thickness) were cut using an ultramicrotome, collected on uncoated copper grids, stained with both uranyl acetate and lead citrate, and then observed using a Hitachi H-7650 TEM operating at $60 \mathrm{kV}$. Nonserial cross-sections from each sample were analyzed.

Measurement of $\mathrm{Chl}$ content. The $\mathrm{Chl}$ content of leaves was examined using the $95 \%$ ethanol extraction method (Knudson et al. 1977). A total of $100 \mathrm{mg}$ of fresh leaves was cut into thin filaments and then placed into a 50-ml graduated tube containing $20 \mathrm{ml}$ of $95 \%$ ethanol for extraction under dark conditions. All treatments were repeated three times. When the leaves became completely white, the absorbance was recorded at 665 and $649 \mathrm{~nm}$ using an ultraviolet (UV) spectrophotometer. The Chl content of the leaves was then calculated in accordance with the following formulae: Chl $\mathrm{a}=13.95 \mathrm{OD}_{665}-6.88 \mathrm{OD}_{649} ; \mathrm{Chl} \mathrm{b}=24.96 \mathrm{OD}_{649}-7.32 \mathrm{OD}_{665}$; and Chl content $(\mathrm{mg} / \mathrm{g})=($ concentration of $\mathrm{Chl} \times$ extraction volume $\times$ dilution factor)/fresh sample quality (Richardson et al. 2002).

Measurement of Chl fluorescence parameters. All measurements of Chl fluorescence parameters of detached leaves were performed using a MINI-Imaging-PAM fluorometer (Walz, Effeltrich, Germany). Leaves collected in the field were directly placed onto wet filter paper; all treatments were repeated three times. Minimal fluorescence $\left(F_{o}\right)$ was measured as the average of the fluorescence signals under a weak measuring light $\left(0.1 \mu \mathrm{mol} / \mathrm{m}^{2} / \mathrm{s}^{1}\right)$. Maximal fluorescence $\left(\mathrm{F}_{\mathrm{m}}\right)$ was induced by a saturation pulse of light (approximately $4,800 \mu \mathrm{mol} / \mathrm{m}^{2} / \mathrm{s}^{1}$ ). Other related fluorescence parameters $\left(\mathrm{F}_{\mathrm{m}}, \mathrm{F}_{\mathrm{o}}, \mathrm{F}_{\mathrm{v}}\right.$, etc.) were also measured. The blade surface absorptivity (Abs) was calculated as Abs = 1 - R / NIR, where $R$ is the red $(\lambda=650 \mathrm{~nm})$ reflectance and NIR is the nearinfrared $(\lambda=780 \mathrm{~nm})$ reflectance (Dima et al. 2006). The maximum quantum efficiency of photosystem II (PSII) $\left(\mathrm{F}_{\mathrm{v}} / \mathrm{F}_{\mathrm{m}}\right)$ was determined as $F_{v} / F_{m}=\left(F_{m}-F_{o}\right) / F_{m}$; the photochemical quenching coefficient (qp) was calculated as $q p=\left(F_{m}^{\prime}-F\right) /\left(F_{m}^{\prime}-F o\right)($ Genty et al. 1989); the nonphotochemical quenching coefficient (NPQ) was calculated as NPQ $=\mathrm{F}_{\mathrm{m}} / \mathrm{F}_{\mathrm{m}}-1$ (Bilger and Björkman 1990); and the actual quantum efficiency of PSII $\left(\Phi_{\mathrm{PSII}}\right)$ was determined as $\Phi_{\text {PSII }}=\left(F_{m}^{\prime}-F_{s}\right) / F_{m}^{\prime}$ (Genty et al. 1989; Tan and Whitlow, 2001).

Detection of sugar and starch content. The starch content of jujube leaves was measured using a Starch Assay Kit SA-20 (Sigma, St. Louis) in accordance with the manufacturer's instructions. A total of $0.3 \mathrm{~g}$ of leaves was finely powdered and
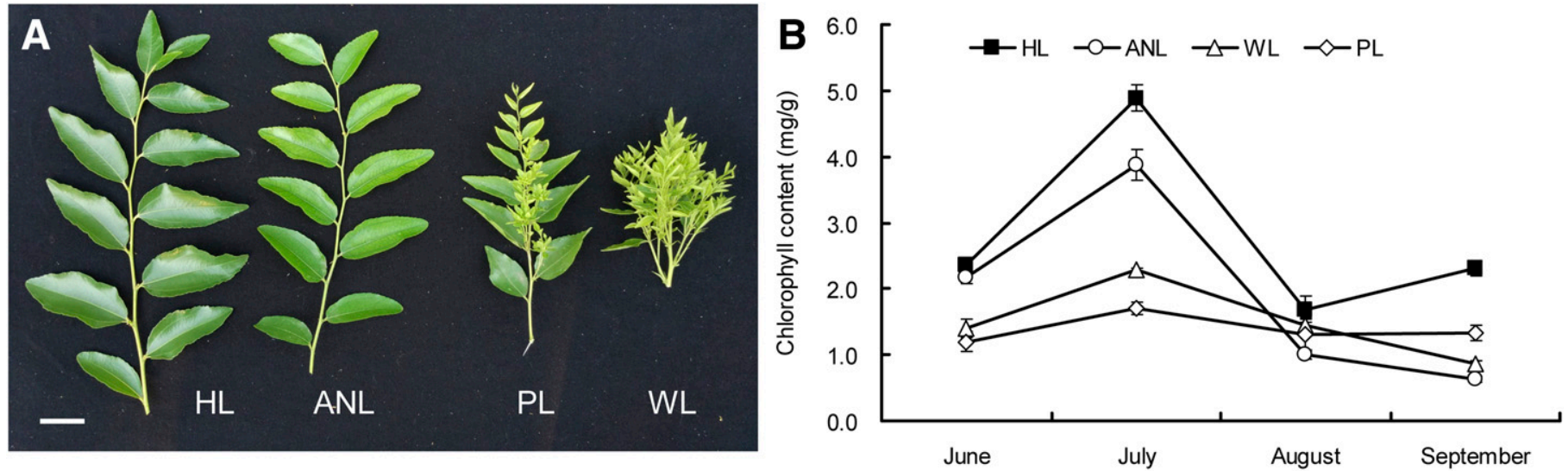

C

D
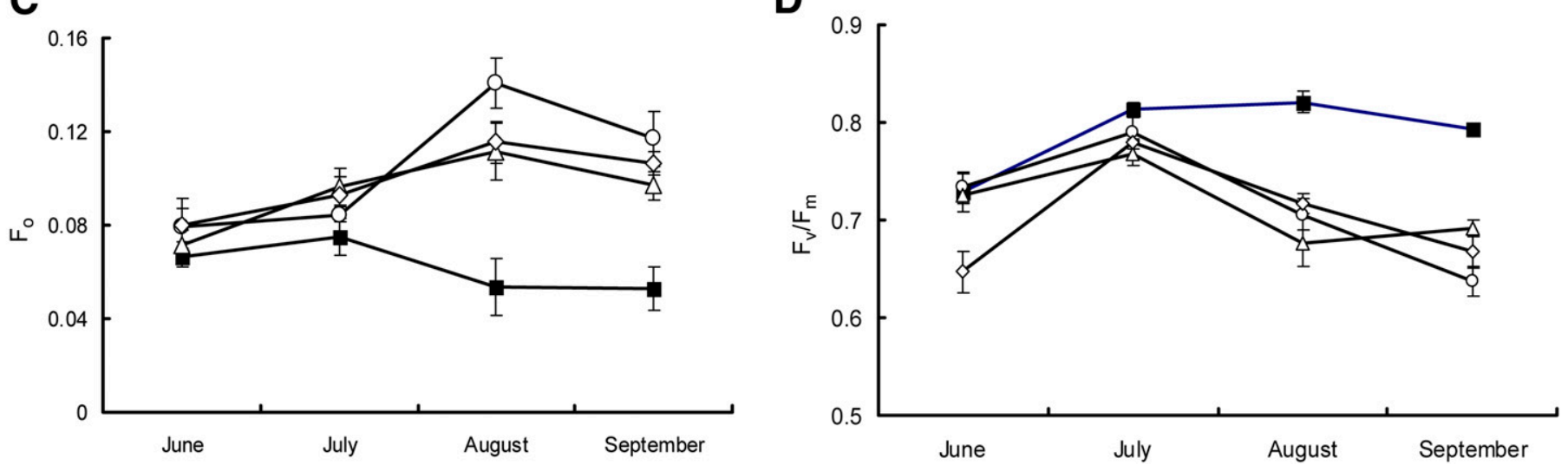

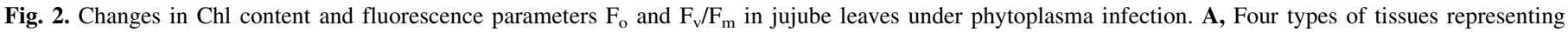

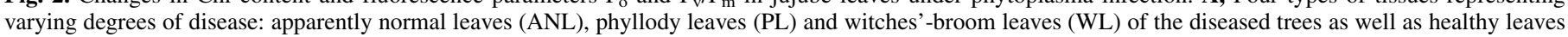

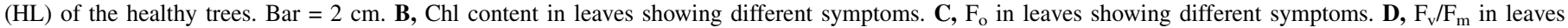
showing different symptoms. Each sample consisted of three biological replicates. 
dissolved in $25 \mathrm{ml}$ of $\mathrm{ddH}_{2} \mathrm{O}$ by autoclave at $135^{\circ} \mathrm{C}$ for $1 \mathrm{~h}$, and then $\mathrm{ddH}_{2} \mathrm{O}$ was added to a total volume of $100 \mathrm{ml}$. Then, mix $1 \mathrm{ml}$ of the above sample and $1 \mathrm{ml}$ of starch assay reagent and incubate for $15 \mathrm{~min}$ at $60^{\circ} \mathrm{C}$. The starch assay reagent blank, sample blank, and glucose assay reagent blank were regarded as three blank controls, respectively. Next, take $0.5 \mathrm{ml}$ from the test above and $1 \mathrm{ml}$ of glucose assay reagent to mix and incubate for $15 \mathrm{~min}$ at room temperature. The absorbances of different samples were measured at $340 \mathrm{~nm}$.

The leaf sugar content was measured using HPLC (Ouchemoukh et al. 2010). A total of $0.25 \mathrm{~g}$ of leaf tissue was finely powdered and then dissolved in $25 \mathrm{ml}$ of $\mathrm{ddH}_{2} \mathrm{O}$ by bathing in $80^{\circ} \mathrm{C}$ for approximately $2 \mathrm{~h}$. The solution was then filtered and concentrated to dry, after which the solution was completely dissolved using $5 \mathrm{ml}$ of $\mathrm{ddH}_{2} \mathrm{O}$ over a $0.45-\mu \mathrm{m}$ water film for testing. This configuration was then loaded onto a Prevail Carbohydrate ES Column $(4.6 \times$ $250 \mathrm{~mm}, 5 \mu \mathrm{m})$ and then eluted at $1 \mathrm{ml} / \mathrm{min}$ at $30^{\circ} \mathrm{C}$. The mobile phase consisted of $75 \%$ acetonitrile. The standard curve was prepared by mixing glucose, fructose, and sucrose. All samples were repeated and measured three times.

Total DNA/RNA extraction and first-strand cDNA synthesis. Total genomic DNA was extracted using the cetyltrimethylammonium bromide (CTAB) method (Liu et al. 2016). Total RNA was extracted using an RNAprep Pure Plant Kit (TIANGEN) according to the manufacturer's protocol, and genomic DNA was removed using RNase-free DNase I (TIANGEN). DNA and RNA concentrations and purity were checked using a NanoDrop2000 spectrophotometer. First-strand cDNA was synthesized by reverse transcribing 500 ng of total RNA with FastQuant RT Super Mix Kit (TIANGEN). The cDNA was subsequently used as the template for qRT-PCR.

qRT-PCR analysis. The expression of genes related to photosynthesis, starch synthase and carbohydrate metabolism and phytoplasma content were detected using qRT-PCR. The primers used in this study are listed in Supplementary Table S1. The PCR products were amplified in triplicate using the Bio-Rad iQ 5 with TransStart Top Green qPCR SuperMix AQ131 (TransGen Biotech, China) in $20-\mu l$ reactions. The reaction system contained $10 \mu$ l of $2 x$ TransStart Top Green qPCR SuperMix, $0.4 \mu \mathrm{l}$ of each primer at $10 \mu \mathrm{M}, 8.2 \mu \mathrm{l}$ of $\mathrm{ddH}_{2} \mathrm{O}$, and $1 \mu \mathrm{l}$ of diluted DNA or cDNA. The thermal profile for qRT-PCR consisted of preincubation for $30 \mathrm{~s}$ at $95^{\circ} \mathrm{C}$ followed by 40 cycles of $5 \mathrm{~s}$ at $95^{\circ} \mathrm{C}, 10 \mathrm{~s}$ at $53^{\circ} \mathrm{C}$, and $10 \mathrm{~s}$ at $72^{\circ} \mathrm{C}$. Three biological replicates were performed for each treatment. Threshold cycle values were calculated using iCycler software, and ZjACT was used as an internal control (Bu et al. 2016). Relative expression levels were calculated in accordance with the $2^{-\Delta \Delta C T}$ method (Livak and Schmittgen 2001).

Metabolomic analysis. For each sample, $80 \mathrm{mg}$ of the abovereported leaves was frozen in liquid nitrogen and lyophilized. Six biological replicates were used for gas chromatography mass spectrometry analysis. The targeted metabolites were performed by using the Shanghai Applied Protein Technology Co., Ltd. (http:// www.aptbiotech.com/). The metabolomics procedures, data collection and analysis were according to previous study (Cai et al. 2015).

Statistical analysis. The results represented the mean value of three independent replicates and sample variability was indicated as the standard deviation of the means. One-way analysis of variance followed by Duncan's new multiple range test was employed to examine the differences between means using SPSS17.0.

\section{RESULTS}

Phytoplasma detection in tissues exhibiting varying degrees of disease. To identify the disease severity of the jujube tissues, the phytoplasma concentration in the different types of
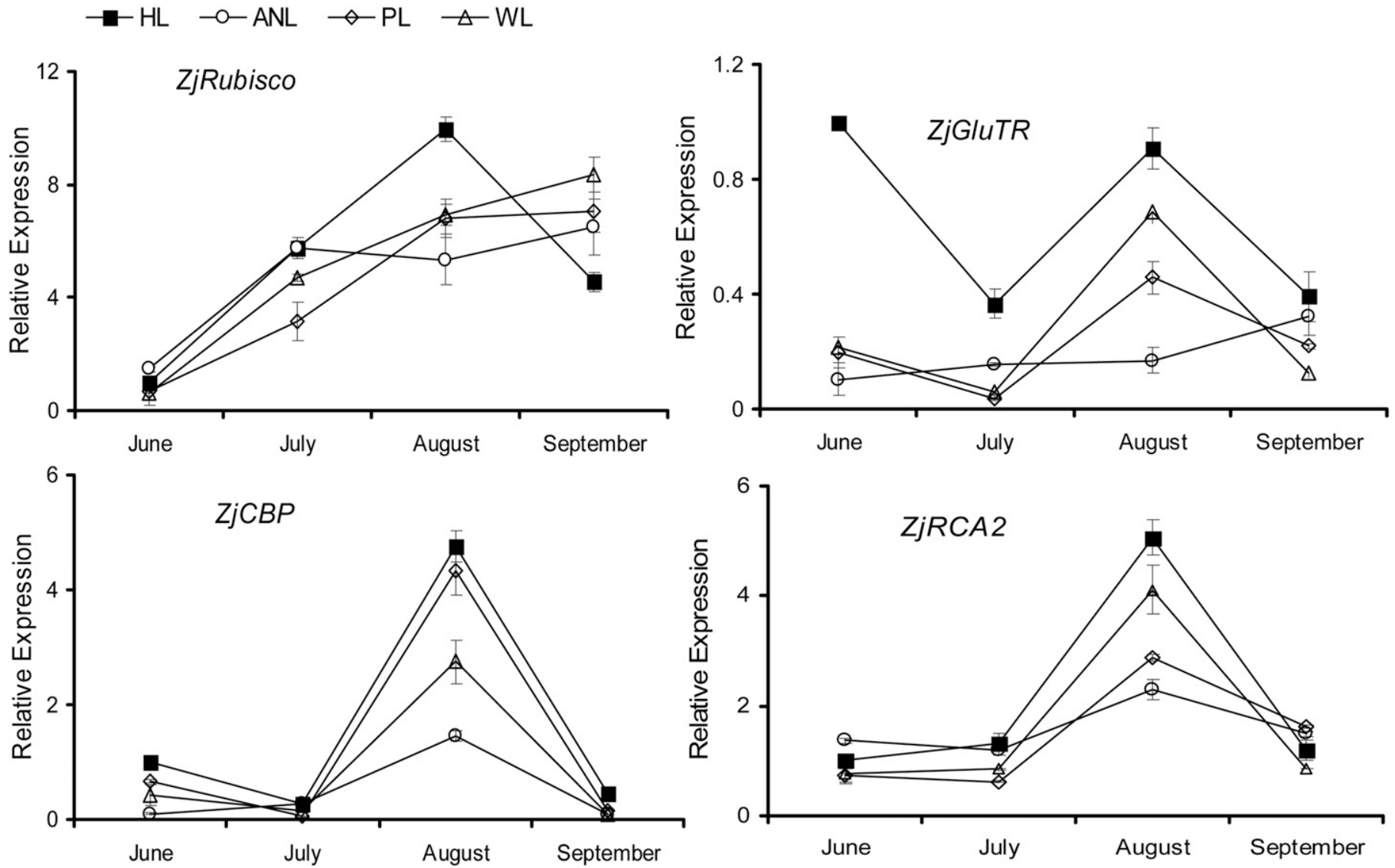

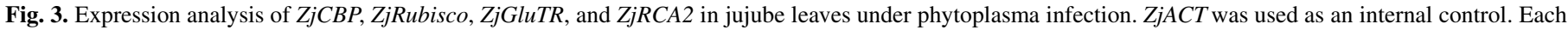
sample consisted of three biological replicates. 
samples was measured at the tissue and molecular levels. DAPI showed no fluorescent spots in the HL, and some spots of JWB phytoplasmas were observed in the ANL (Fig. 1A and B). The fluorescent spots formed a large bright circle in the petiole phloem of the WL and PL (Fig. 1C and D). Meanwhile, TEM demonstrated that phytoplasmas were localized in the sieve elements (SEs) of diseased petiole (Fig. 1E and F). They appeared to be well preserved showing their typical shape, approximately 200 to $400 \mathrm{~nm}$ in size. Correspondingly, the expression of the phytoplasma TMK gene in the WL and PL was also apparently higher than that of the ANL, whereas no expression was detected in the HL (Supplementary Fig. S1).

Effects of phytoplasma infection on $\mathrm{Chl}$ content and $\mathrm{Chl}$ fluorescence parameters. The Chl content of leaves with different
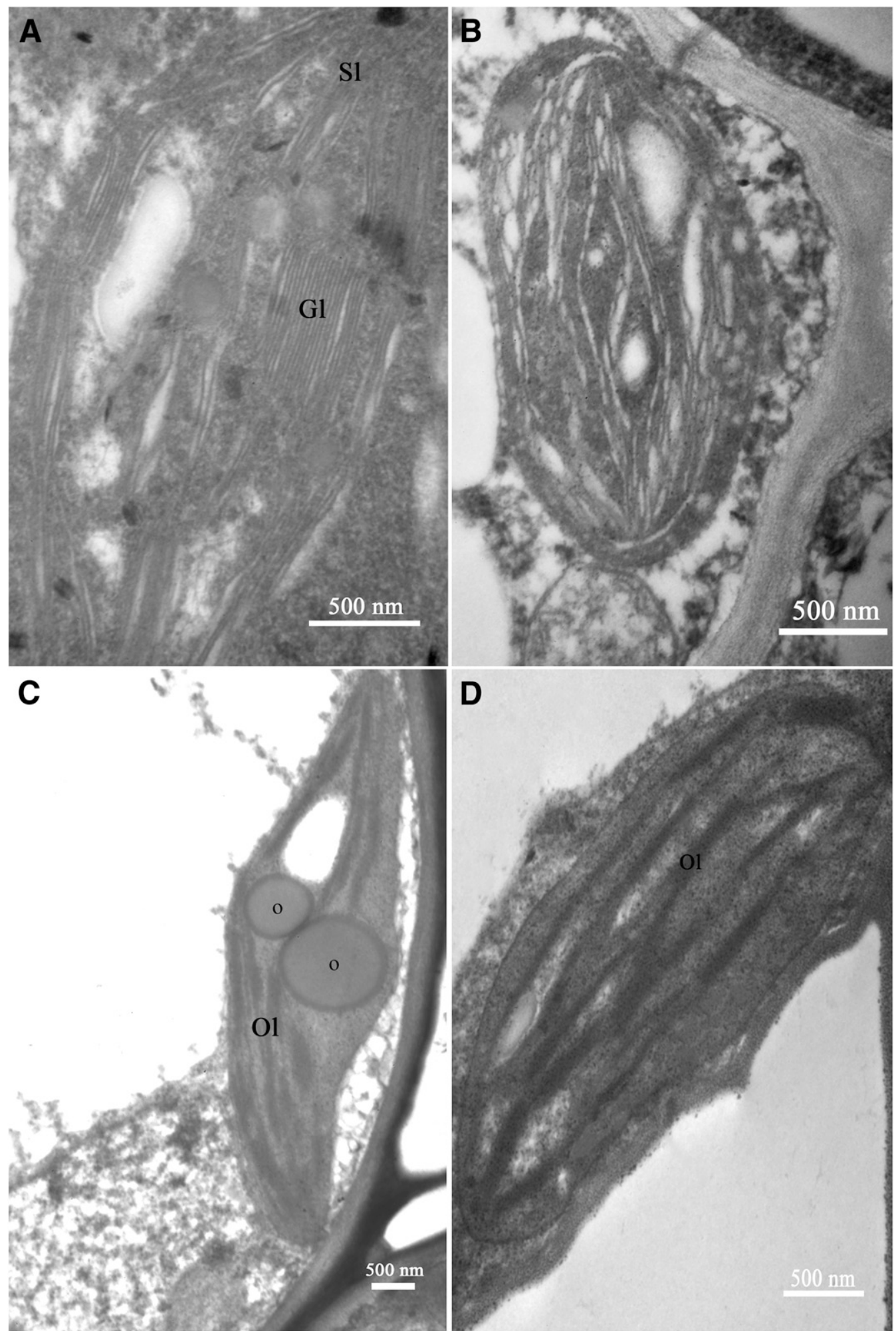

Fig. 4. Phytoplasma infection damaged the chloroplast structure of diseased leaves. A, Chloroplasts of the HL were large, elliptic, and intact, and the lamellar structure was uniform and homogeneous. B, Chloroplasts of the apparently normal leaves. C, Chloroplasts of the phyllody leaves. D, Chloroplasts of the witches'broom leaves. The chloroplasts of serious diseased leaves (C and D) were irregular in shape, and granum layers and stroma lamellae were destroyed. Gl, granum layer; Sl, stroma lamellae; Ol, original lamellar bodies; and O, osmophilic granules. 
symptoms showed similar trends at various developmental periods (Fig. 2B). At the peak period of growth in Chinese jujube (July), the Chl content in all types of leaf samples was highest. There was a slight increase in Chl content during the late growth period in the HL. The Chl content of the diseased leaves was markedly lower during the whole growth period compared with that of the healthy control.
Meanwhile, a series of Chl fluorescence parameters were measured; these parameters are shown in Supplementary Table $S 2 . \mathrm{F}_{\mathrm{v}} / \mathrm{F}_{\mathrm{m}}$ is the maximum photochemical quantum yield of PSII and reflects the internal energy conversion efficiency in the reaction center $(\mathrm{Lu}$ and Zhang 1999). The value of $F_{v} / F_{m}$ is between 0.80 and 0.85 in the absence of stress but is significantly reduced under stress conditions (Murchie and Lawson 2013; Roháček and Barták 1999).
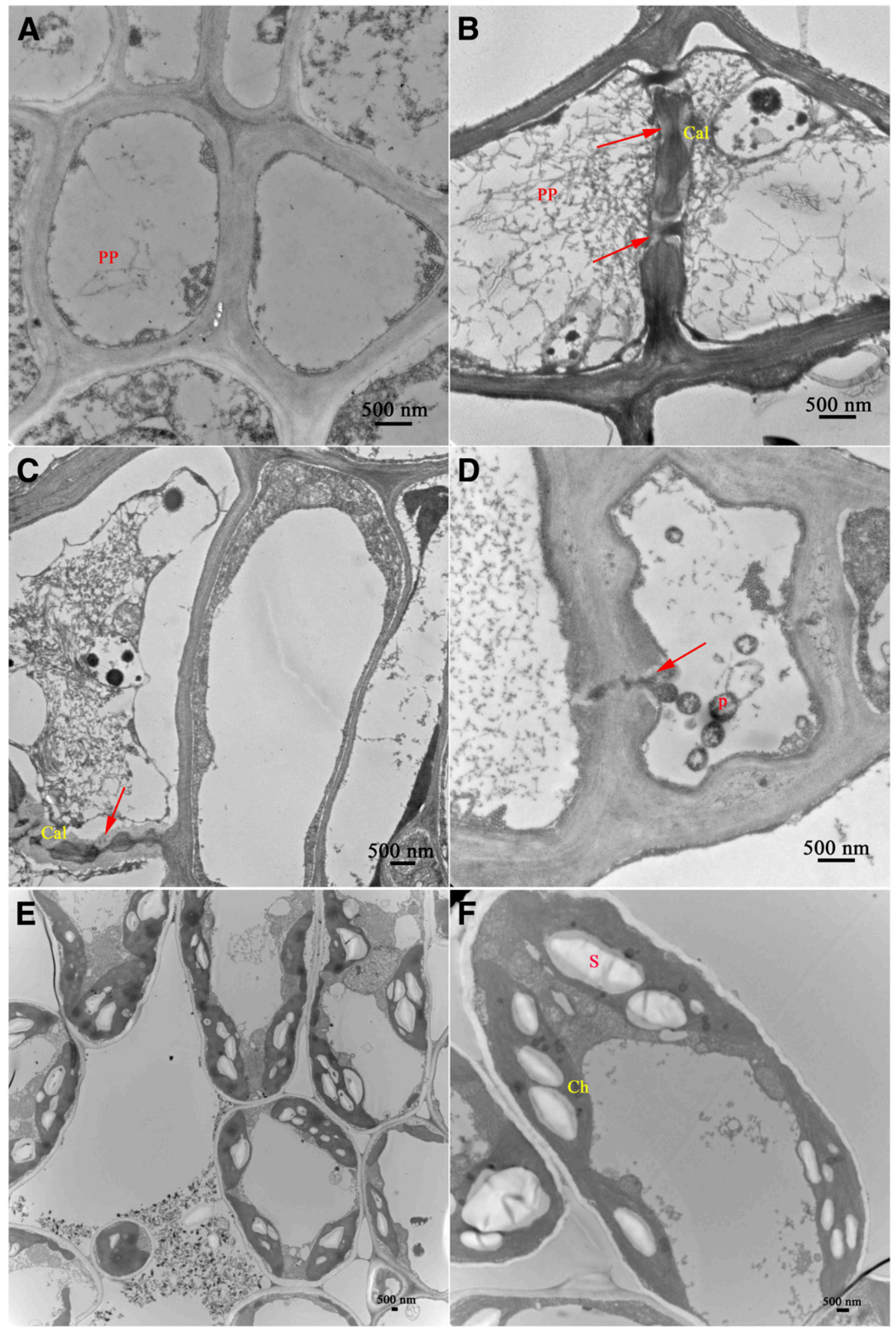

Fig. 5. Changes in the P-proteins of the diseased sieve element (SE). The P-proteins in diseased SEs were transformed into clots of filamentous material. These clots amassed in front of the sieve plates, occluded the sieve pores and enveloped the phytoplasma cells. The sieve pores of the diseased SEs were always occluded and constricted by callose (arrow). Cal, callose; PP, P-proteins; P, phytoplasmas; Ch, chloroplast; S, starch. A, healthy SE; B, C, and D, diseased SEs; E and F, starches in the chloroplasts of healthy leaves $(\mathbf{E})$ and diseased leaves $(\mathbf{F})$. 

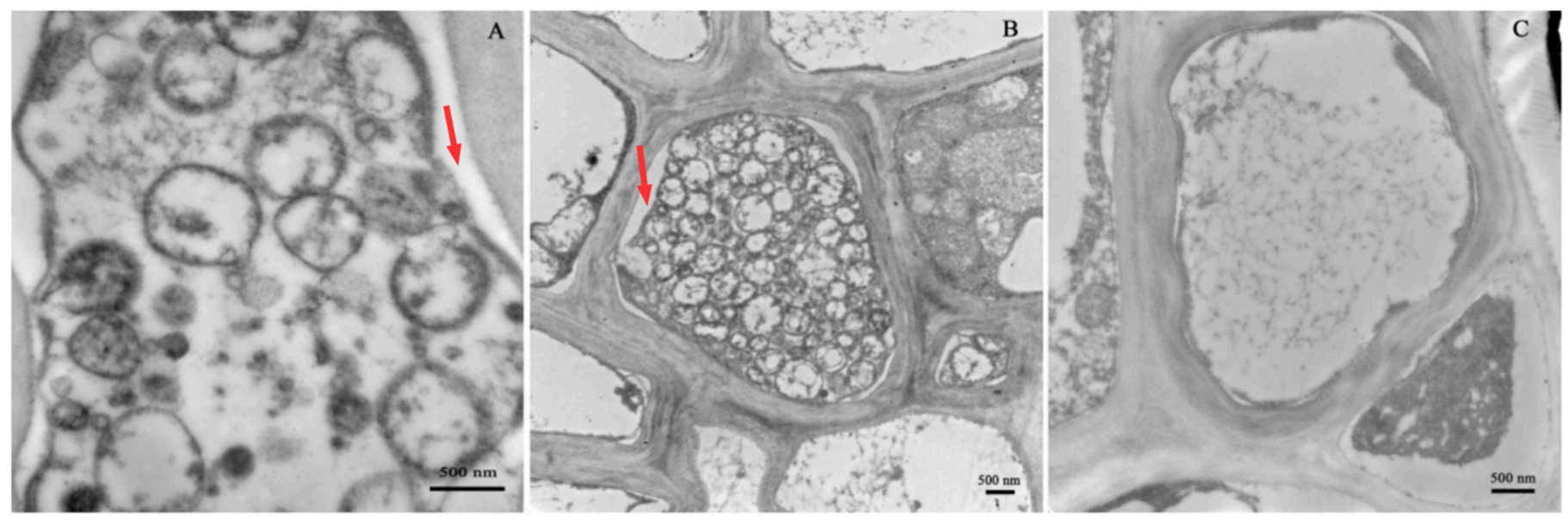

Fig. 6. Changes in the plasma membrane of the diseased sieve element (SE). A, Plasma membrane in a diseased SE; the plasma membrane is deformed and detached from the cell wall (arrow). B, Dense amounts of phytoplasmas were observed in diseased SEs. C, Healthy SE.
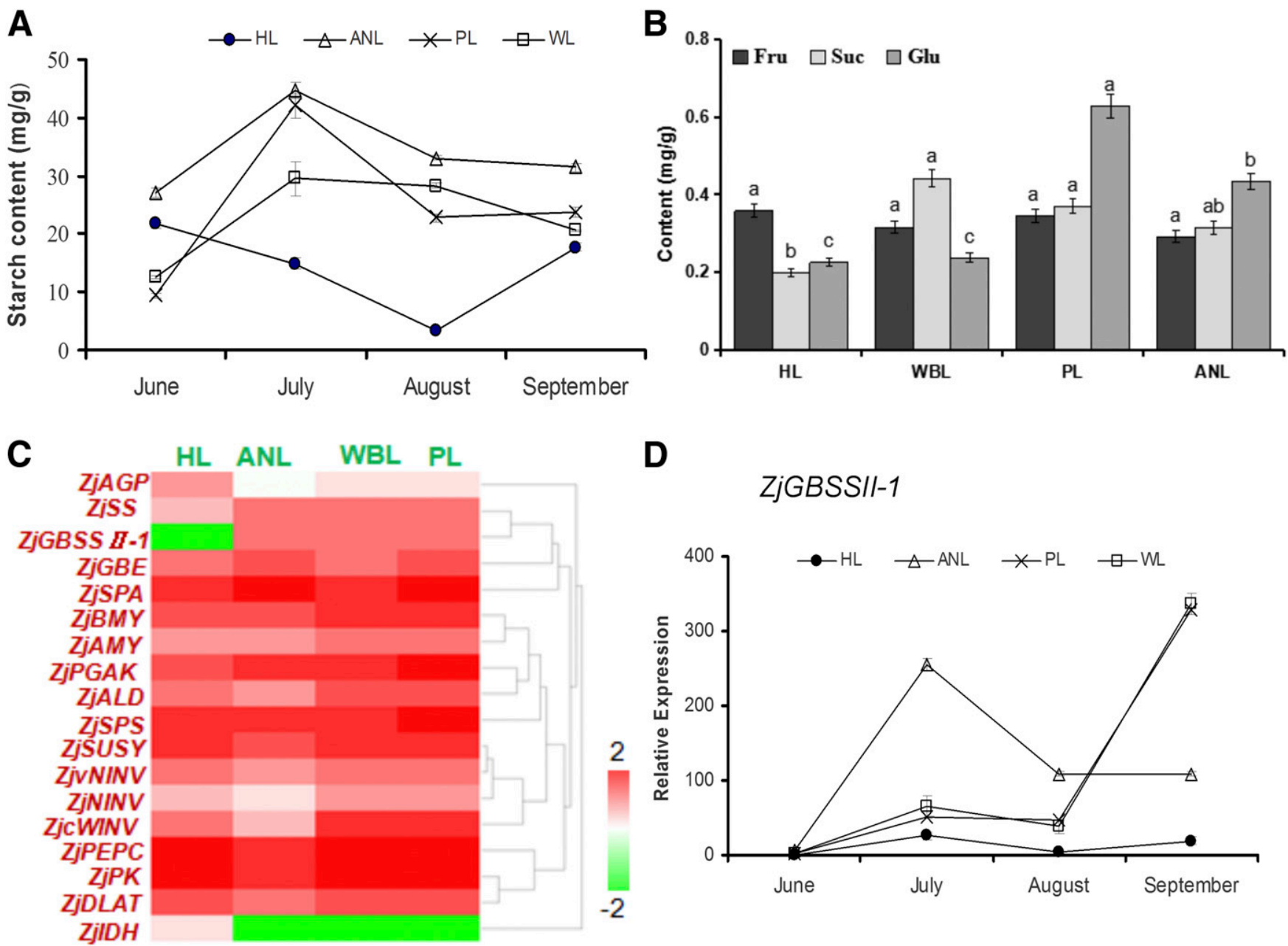

D

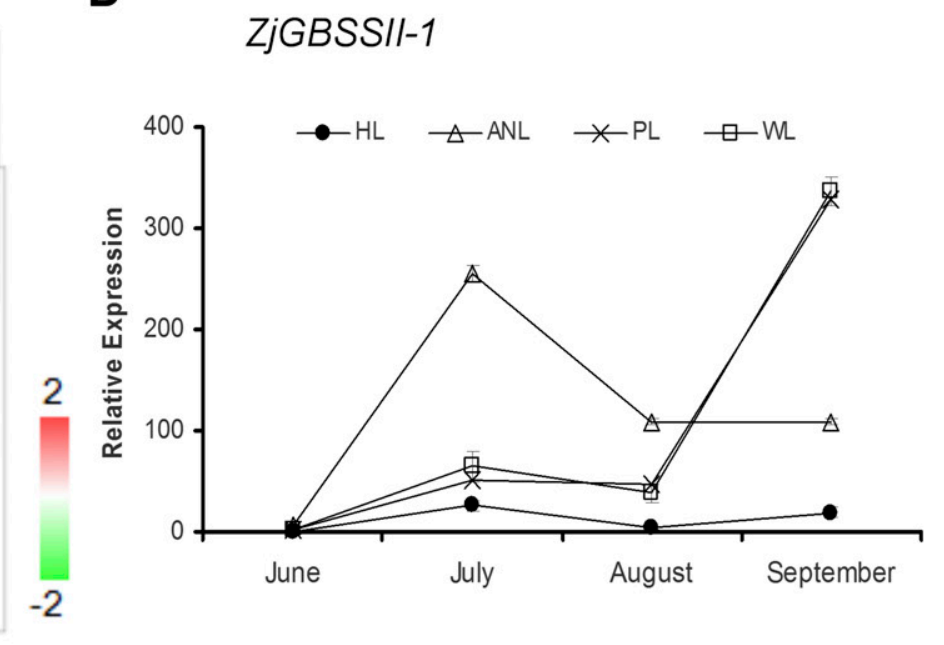

Fig. 7. Phytoplasma infection altered the sugar metabolism of diseased jujube leaves. A, Starch contents of four types of leaf samples. B, Contents of sucrose, glucose and fructose in the four types of leaf samples. C, Relative expression of genes related to starch and sugar metabolism in the four types of leaf samples. The gene expression data were obtained from the transcriptome data, and clustering was performed using Heatmap Illustrator. The color scale ( -2 to 2 in light to dark or green to red) represents the Z-score of the normalized gene expression from the GeneChip data. Dendrograms along the right side of the heat map indicate the hierarchical clustering of genes. RuBP: ribulose bisphosphate; Rubisco: ribulose-1,5-bisphosphate ribulose carboxylase; PGAK: phosphoglycerate kinase; 3-PGA: 3-phosphoglycerate; G3P: glyceraldehyde-3-phosphate; F6P: fructose-6-phosphate; G6P: glucose-6-phosphate; G1P: glucose-1-phosphate; AGP: glucose-1phosphate adenylyl transferase; ADPG: ADP glucose; UDPG: UDP glucose; SS: starch synthase; GBSSII-1: granule-bound starch synthase II-1; GBE: 1,4-alphaglucan branching enzyme; SPA: starch phosphorylase; AMY: alpha-amylase; BMY: beta-amylase; Glc: glucose; Fru: fructose; Suc: sucrose; TPT: triose phosphate/ phosphate translocator; ADL: fructose-bisphosphate aldolase; SPS: sucrose phosphate synthase; SUSY: sucrose synthase; SPP: sucrose phosphatase; Suc-6-P: sucrose-6-phosphate; NINV: alpha-glucosidase; vAINV: acid beta-fructofuranosidase; cWINV: cell wall apoplastic invertase; F1,6BF: fructose-1,6-biphosphate; PEPC: phosphoenolpyruvate carboxylase enzyme; PK: pyruvate kinase; DLAT: dihydrolipoamide acetyltransferase; IDH: isocitrate dehydrogenase; OAA: oxaloacetic acid; PEP: phosphoenolpyruvate; Ac-CoA: acetyl-coenzyme A. D, Up-regulated expression of ZjGBSSII-1 in jujube leaves under phytoplasma stress. Each sample consisted of three biological replicates. 
The $\mathrm{F}_{\mathrm{v}} / \mathrm{F}_{\mathrm{m}}$ values of the HL were the highest and were maintained at approximately 0.80 , whereas those of the diseased leaves clearly decreased during the mid- and late-infection stages (Fig. 2D), which indicates that PSII activity was inhibited.

In addition, the decrease in $\mathrm{F}_{\mathrm{v}} / \mathrm{F}_{\mathrm{m}}$ of diseased jujube leaves was due to the increase in $\mathrm{F}_{\mathrm{o}}$ (Fig. 2C); an increase in $\mathrm{F}_{\mathrm{o}}$ indicates that the energy absorbed by the pigment in the form of heat and fluorescence increases. The results showed that phytoplasma infection could lead to an increase in the energy absorbed by leaves in the form of heat and fluorescence; however, the participation of the photochemical reaction was less, and the thylakoid membrane was damaged to variable degrees.

Phytoplasma infection decreased the expression of genes involved in photosynthesis. To further characterize the effects of phytoplasma infection on photosynthesis, the expression of genes related to photosynthesis were evaluated (Fig. 3). $\mathrm{ZjCBP}$ belongs to the $l h c b$ gene family and is a key component of light-harvesting complex II (LHCII). During the growing season, the expression of $Z j C B P$ in the diseased leaves was significantly lower than that in the $\mathrm{HL}$, which indicates that the light energy capture ability of the diseased leaves was markedly lower than that of the HL. Glutamate$t R N A$ reductase (ZjGluTR) is a recombinant enzyme involved in Chl synthesis, and the activity of this enzyme directly affects the Chl content. The expression of ZjGluTR was significantly lower in the diseased leaves than in the HL, which is consistent with the lower Chl content in the diseased leaves (Fig. 2B).
Ribulose-1,5-bisphosphate carboxylaseloxygenase (Rubisco, EC4.1.1.39) is a key enzyme that regulates photosynthesis, and its activity depends on Rubisco activase (RCA) (Parry et al. 2002, Feller et al. 2008). ZjRCA2 is the critical gene related to Rubisco activity in Chinese jujube (Liu et al. 2016). The expression trends of ZjRubisco and ZjRCA2 in the same kinds of leaves were similar (Fig. 3), which indicates that both were synergistic with respect to photosynthesis. The expression of the two genes in the diseased leaves was lower than that in the healthy one, which suggests that phytoplasma infection reduced the photosynthetic rate of the diseased leaves.

Phytoplasma infection damaged chloroplast and sieveelement structure in diseased leaves. To investigate the effects of phytoplasma infection on photosynthetic structures, the chloroplasts of the mesophyll cells of the healthy and diseased leaves were observed using TEM. The chloroplasts of mesophyll cells in the HL were large and oval shaped and were clearly differentiated, contained fully developed grana that had numerous layers and well-developed stroma lamellae with starch granules (Fig. 4A). On the other hand, in phytoplasma-infected leaves, the chloroplasts decreased in size, and irregular arrangements of thylakoid stacks were clearly observed (Fig. 4B to D). In the chloroplasts of the $\mathrm{PL}$ and WL, the structures of the grana and stroma lamellae were destroyed (Fig. 4C and D).

At the same time, changes in both the plasma membrane and Pproteins of the diseased petiole sieve elements were also observed

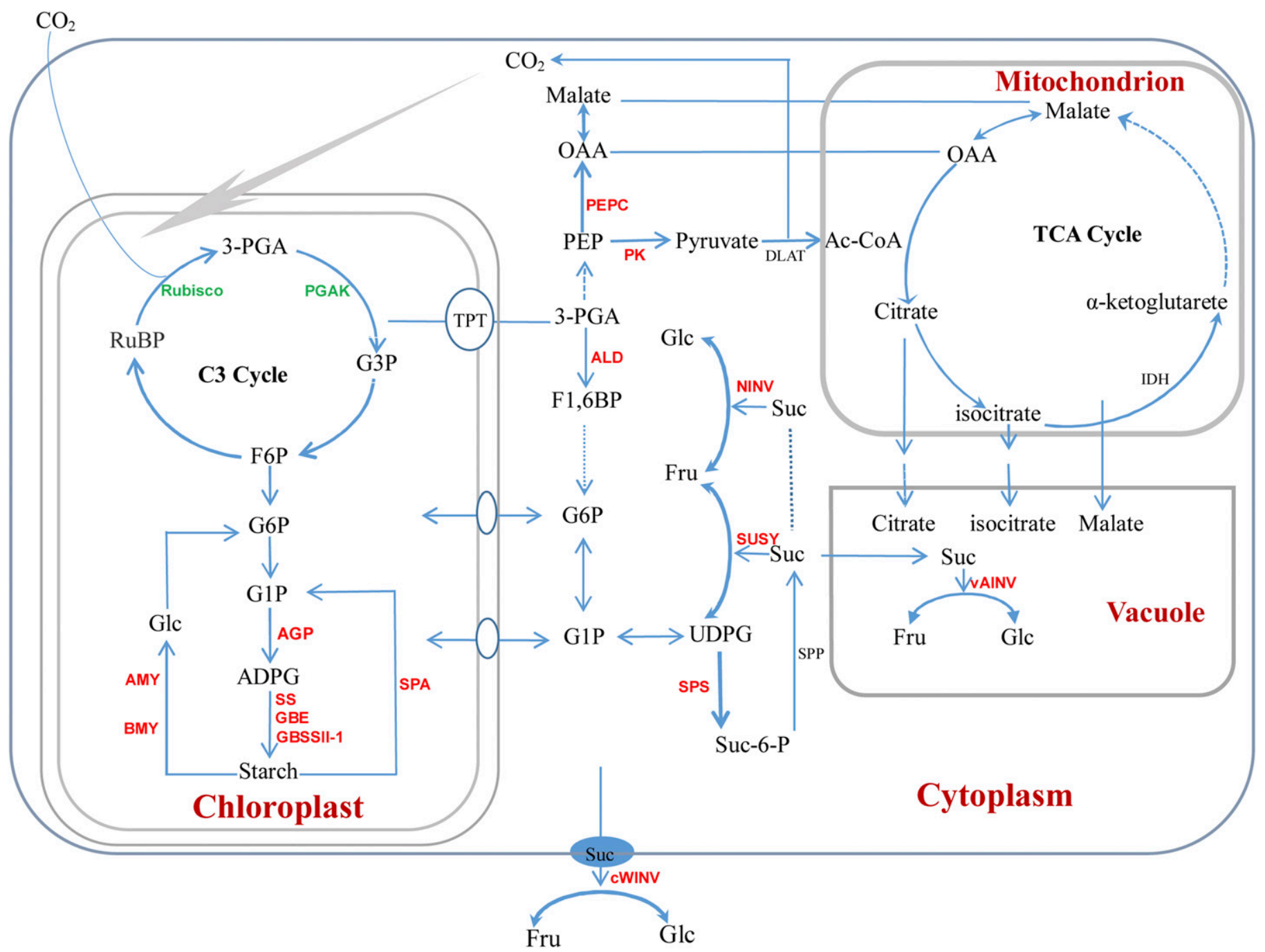

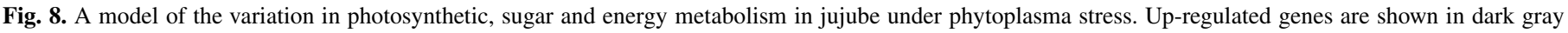
(red); down-regulated genes are shown in light gray (green). 
(Figs. 5 and 6). The plasma membrane of SEs in healthy samples was smoothly appressed to the cell wall, and homogeneously distributed P-protein filaments were present in the lumen. On the other hand, the plasma membrane of diseased SEs was deformed and detached from the cell wall; callose deposition on the sieve plates was induced, and P-proteins clustered into filamentous clots that amassed on the sieve plates and occluded the sieve pores (Figs. 5 and 6).

Phytoplasma infection stimulated carbohydrate accumulation in diseased leaves. Furtherly, we found that the starch content in the diseased leaves was significantly higher than that in the HL, and the starch content in the ANL was highest (Fig. 7A, Supplementary Table S3). The starch content in the HL notably decreased during the rapid growth period (from June to July), while the starch content in all the diseased leaves dramatically increased. At the transcriptional level, the expression profiling analysis revealed that the genes involved in starch synthesis, including granule-bound starch synthase II-1 (GSBBII-1) and starch synthase (SS), were expressed at a dramatically higher level in the diseased leaves (Fig. 7C and D, Supplementary Fig. S2). These results were in accordance with the increased content of starch in the diseased leaves.

The expression of many genes related to sugar metabolisms were also enhanced in the diseased leaves (Fig. 8, Supplementary Tables $\mathrm{S} 4$ and S5). The expression levels of starch-degrading genes (starch phosphorylase (SPA), alpha-amylase (AMY), and beta-amylase $(B M Y)$ ) and sucrose-catabolism genes (sucrose synthase (SUSY) and invertase (NINV, vAINV, and $c W I N V)$ ) were higher, meaning that more glucose and fructose were produced. Moreover, the expression of sucrose phosphate synthase (SPS), which plays key roles in the sucrose synthesis process, markedly increased in the diseased leaves, which also contributed to sucrose accumulation. Correspondingly, HPLC results showed that the contents of sucrose and glucose in the diseased leaves were much higher than those of the HL (Fig. 7B).
Phytoplasma infection stimulated amino acids and energy metabolism in diseased leaves. Comparative metabolite analysis showed that the contents of most amino acids detected were significantly increased in diseased leaves (Fig. 9, Supplementary Table S6), indicating that amino acid metabolism was partially enhanced at the metabolic level. Beyond their role as building blocks of proteins, amino acids participate in many metabolic processes, such as the tricarboxylic acid (TCA) or glycolysis cycle. Meanwhile, phosphoenolpyruvate carboxylase enzyme (PEPC) and pyruvate kinase $(P K)$ in the diseased leaves were expressed at much higher levels than those in the HL (Fig. 7C); these enzymes supply sufficient oxaloacetic acid (OAA) and acetyl-coenzyme A (Ac-CoA) for TCA cycle metabolism. Furthermore, the expression of isocitrate dehydrogenase (IDH), which is a critical enzyme in the TCA cycle, was also higher in the diseased leaves than the HL. These two steps constitute the critical irreversible rate-limiting step of the TCA cycle. As summarized in Figure 8, the increased expression of related genes indicated that respiration in the diseased leaves was strengthened and that a large amount of energy was released.

\section{DISCUSSION}

In general, diseased jujube trees in the field die after 3 to 4 years. However, the diseased jujube seedlings can be subcultured in the medium without hormones and survive for many years under a continuous nutrient supply in the laboratory. The long-term culture of diseased jujube seedlings can be performed in vitro, indicating that an adequate nutrient supply is important to their growth. Therefore, the effects of phytoplasma on jujube photosynthetic, carbohydrate and energy metabolisms were demonstrated at the structural, physiological and molecular levels. Phytoplasma infection disturbed the operation and formation of the photosynthate of jujube trees, disrupted sugar metabolism and, in particular,

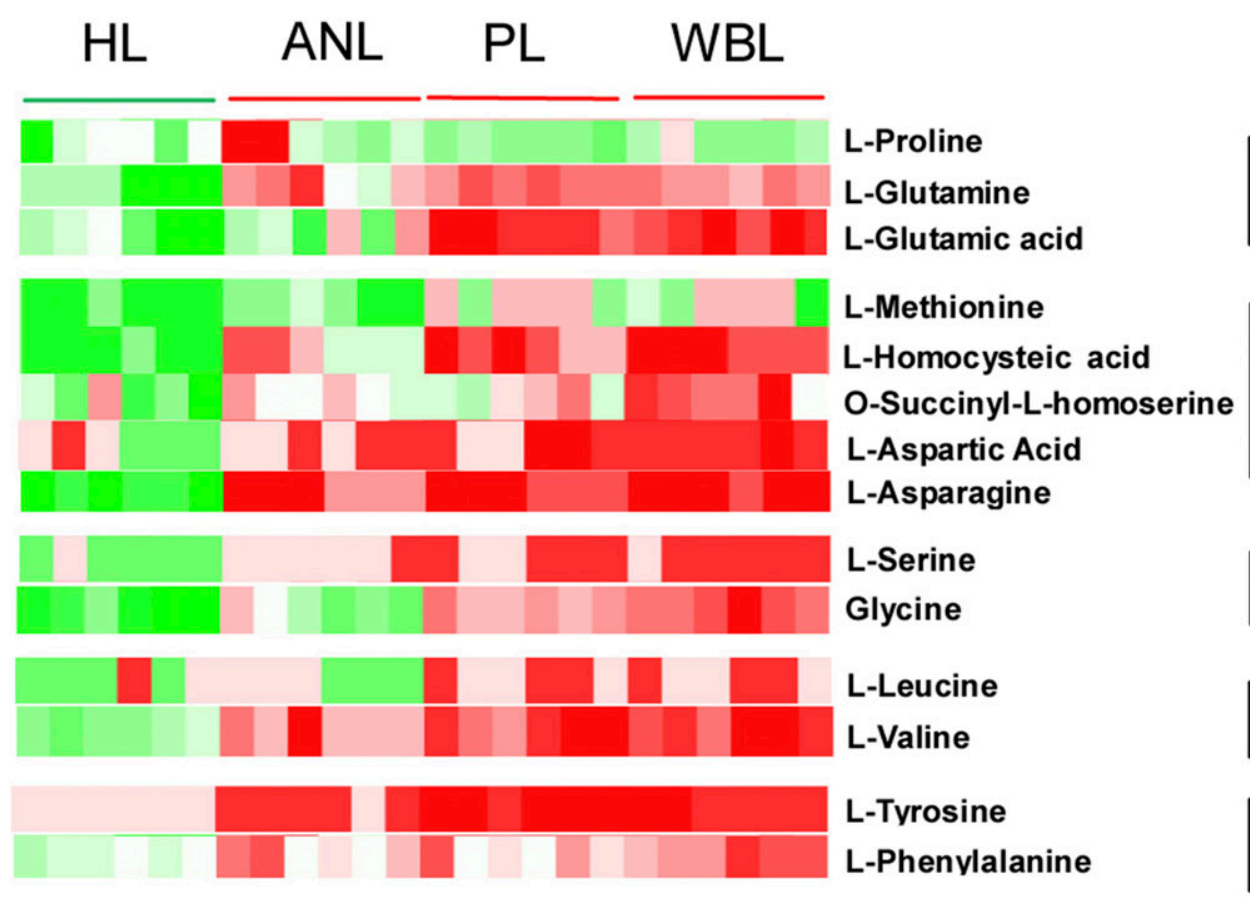

Glutamic acid group

Aspartic acid group

\section{Serine group}

\section{Pyruvic acid group}

\section{Aromatic amino acid}
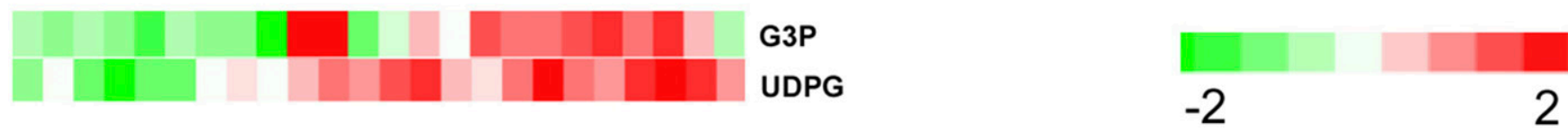

Fig. 9. Changes in amino acids and metabolites in jujube leaves under phytoplasma infection. The color scale ( -2 to 2 in light to dark or green to red) represents the Z-score of the normalized metabolite abundance from the metabolomics data. G3P, glyceraldehyde-3-phosphate; and UDPG, UDP glucose. 
stimulated the abnormal accumulation of starch in the chloroplasts. The increase in sugar content temporarily benefits phytoplasma proliferation; however, the excessive damage to the structure and basal metabolism of the host jujube trees significantly reduced their subsequent photosynthetic products. The diseased jujube trees may be exhausted gradually under continuous phytoplasma invasion because of the lack of a sustainable and sufficient nutrient supply.

After being infected by phytoplasma, the host plant exhibited increased respiration, cell wall enhancement, and synthesis of some defense complexes; more carbohydrates and free amino acids are essential for these metabolic activities to provide energy to the host plant (An 2002; Hou 2012). Photosynthetic products are first used for the synthesis of sucrose, which is regulated by a series of genes. When the expression of genes related to sucrose synthesis reached their threshold, the breakdown of sucrose and the synthesis of starch were stimulated, and sucrose was broken down into fructose and glucose. The large accumulation of blocked glucose and sucrose unloading was caused by the host preference for fructose (Andre et al. 2005). This phenomenon could explain why the sucrose and glucose contents in diseased jujube significantly increased; however, the fructose content did not differ from that of healthy jujube. In addition, the enrichment of soluble sugar and amino acids in diseased jujube may also function as an osmotic adjustment. However, the soluble sugar content in phytoplasma-infected cherry leaves was not significantly different from that of healthy ones (Tan et al. 2015).

Chl fluorescence is one of the most useful tools for measuring changes in PSII under abiotic and biotic stress conditions (Murchie and Lawson 2013). $F_{o}$ represents the energy absorbed by the pigment; this energy is not involved in the photochemical reactions. An increase in the $F_{o}$ values indicates that the energy in the form of heat and fluorescence increases. The greater the increase in $F_{o}$ is, the more severe the damage to the thylakoid membrane in the leaf ( $\mathrm{Wu}$ et al. 2014). There appears to be a consistent pattern of changes in $F_{o}$ and $\mathrm{F}_{\mathrm{v}} / \mathrm{F}_{\mathrm{m}}$ in present and previous studies (Maust et al. 2003; Tan et al. 2015). We observed that the structures of the grana and stroma lamellae of chloroplasts in diseased jujube leaves were destroyed and formed original lamellae, and the number of starch granules increased in the diseased leaves. The disorganization of thylakoids in the diseased leaves directly lowered their Chl content.

The structural modification of host tissue is triggered by phytoplasma infection (Musetti et al. 2016; Rudzińska-Langwald and Kamińska 2001; Santi et al. 2013). It has been hypothesized that the cytological relationship between phytoplasmas and SEs is indispensable for the pathogenicity of phytoplasmas (Christensen et al. 2005). Phytoplasmas seem to be in close contact with the plasma membrane (Marcone et al. 2000). In this study, some irreversible changes in the plasma membrane and P-proteins of the diseased samples were also observed (Fig. 6). The typical symptoms of plasma membranes and phytoplasma status in diseased jujube leaves matched with those described in tomato (Buxa et al. 2015). Phloem impairment in diseased leaves has also been reported for other phytoplasma diseases and is caused by the occlusion of SEs due to phloem-protein agglutination and callose deposition, followed by necrosis and the collapse of SEs (Lee et al. 2000; Musetti et al. 2016; Pagliari et al. 2016).

Phytoplasmas are phloem-restricted prokaryotes, and their proliferation probably inhibits phloem transport, e.g., carbohydrates synthesized by leaves could not be transferred to other sink organs. Photosynthesis-related genes in the HL always exhibited higher expression than did those in the diseased leaves (Fig. 3), which suggests that the photosynthetic capacity in the HL was higher than that in the diseased leaves. Therefore, the decreasing starch content in the HL during the rapid growth period (Fig. 7A) indicated that the photosynthetic product of source leaves was degraded and transported to support the growth of sink organs such as flowers and fruits. On the contrary, the photosynthetic product in the source diseased leaves was accumulated, which subsequently caused starch accumulations (Fig. 7) and inhibited photosynthesis (Fig. 2). The accumulation of photosynthetic product in diseased tissues contributed to their vigorous and excessive growth and led to the typical symptoms of JWB. In fall, the healthy jujube trees began to defoliate and go dormant, however the diseased tissues continue to grow under the condition of freezing temperature and water shortage. Then adequate photosynthetic products cannot be further synthetized in diseased trees, and the accumulated nutrients may be exhausted gradually during winter. Afterward, the diseased organs died on the tree, which caused the typical symptoms of the lack of defoliation during winter. More evidence is needed in our future study to highlight the significance of the transport blockage of phloem during the pathogenic process of phytoplasmas.

\section{LITERATURE CITED}

An, X. M. 2002. Studies on isolation and expression of members of invertase gene family from citrus. Zhejiang University, Hangzhou.

Andre, A., Maucourt, M., Moing, A., Rolin, D., and Renaudin, J. 2005. Sugar import and phytopathogenicity of Spiroplasma citri: Glucose and fructose play distinct roles. Mol. Plant-Microbe Interact. 18:33-42.

Bai, X., Zhang, J., Ewing, A., Miller, S. A., Radek, A. J., Shevchenko, D. V., and Hogenhout, S. A. 2006. Living with genome instability: The adaptation of phytoplasmas to diverse environments of their insect and plant hosts. J. Bacteriol. 188:3682-3696.

Bertamini, M., Nedunchezhian, N., Tomasi, F., and Grando, M. S. 2002. Phytoplasma [Stolbur-subgroup (Bois Noir-BN)] infection inhibits photosynthetic pigments, ribulose-1, 5-bisphosphate carboxylase and photosynthetic activities in field grown grapevine (Vitis vinifera L. cv. Chardonnay) leaves. Physiol. Mol. Plant Pathol. 61:357-366.

Bilger, W., and Björkman, O. 1990. Role of the xanthophyll cycle in photoprotection elucidated by measurements of light-induced absorbance changes, fluorescence and photosynthesis in leaves of Hedera canariensis. Photosynth. Res. 25:173-185.

Bu, J., Zhao, J., and Liu, M. 2016. Expression stabilities of candidate reference genes for RT-qPCR in Chinese Jujube (Ziziphus jujuba Mill.) under a variety of conditions. PLoS One 11:e0154212.

Buxa, S. V., Degola, F., Polizzotto, R., Marco, F. D., Loschi, A., Kogel, K. H., and Musetti, R. 2015. Phytoplasma infection in tomato is associated with re-organization of plasma membrane, ER stacks, and actin filaments in sieve elements. Front. Plant Sci. 6:650.

Cai, Y., Weng, K., Guo, Y., Peng, J., and Zhu, Z. 2015. An integrated targeted metabolomic platform for high-throughput metabolite profiling and automated data processing. Metabolomics 11:1575-1586.

Christensen, N. M., Axelsen, K. B., Nicolaisen, M., and Schulz, A. 2005. Phytoplasmas and their interactions with hosts. Trends Plant Sci. 10: 526-535.

Cséke, C., and Buchanan, B. B. 1986. Regulation of the formation and utilization of photosynthate in leaves. Biochimica et Biophysica Acta (BBA) Rev. Bioenerg. 853:43-63.

Dima, E., Manetas, Y., and Psaras, G. K. 2006. Chlorophyll distribution pattern in inner stem tissues: evidence from epifluorescence microscopy and reflectance measurements in 20 woody species. Trees (Berl.) 20:515-521.

Feller, U., Anders, I., and Mae, T. 2008. Rubiscolytics: Fate of Rubisco after its enzymatic function in a cell is terminated. J. Exp. Bot. 59:1615-1624.

Genty, B., Briantais, J. M., and Baker, N. R. 1989. The relationship between the quantum yield of photosynthetic electron transport and quenching of chlorophyll fluorescence. Biochimica et Biophysica Acta (BBA) Gen. Subjects 990:87-92.

Gurr, G. M., Johnson, A. C., Ash, G. J., Wilson, B. A., Ero, M. M., Pilotti, C. A., and You, M. S. 2016. Coconut lethal yellowing diseases: A phytoplasma threat to palms of global economic and social significance. Front. Plant Sci. 7:1521.

Hou, J. F. 2012. Studies on the sucrose contents of fresh seeds and functional analysis of key genes involved in sugar accumulation in soybean. Nanjing Agricultural University, Nanjing.

Knudson, L. L., Tibbitts, T. W., and Edwards, G. E. 1977. Measurement of ozone injury by determination of leaf chlorophyll concentration. Plant Physiol. 60:606-608.

Lee, I. M., Davis, R. E., and Gundersen-Rindal, D. E. 2000. Phytoplasma: Phytopathogenic mollicutes 1. Annu. Rev. Microbiol. 54:221-255.

Liu, Z., Zhao, J., and Liu, M. 2016. Photosynthetic responses to phytoplasma infection in Chinese jujube. Plant Physiol. Biochem. 105:12-20.

Livak, K. J., and Schmittgen, T. D. 2001. Analysis of relative gene expression data using real-time quantitative PCR and the $2^{-\Delta \Delta C T}$ method. Methods 25: 402-408. 
Lu, C. M., and Zhang, J. H. 1999. Effects of water stress on photosystem II photochemistry and its thermostability in wheat plants. J. Exp. Bot. 50: 1199-1206.

Marcone, C., Lee, I. M., Davis, R. E., Ragozzino, A., and Seemüller, E. 2000. Classification of aster yellows-group phytoplasmas based on combined analyses of rRNA and tuf gene sequences. Int. J. Syst. Evol. Microbiol. 50: 1703-1713.

Maust, B. E., Espadas, F., Talavera, C., Aguilar, M., Santamaría, J. M., and Oropeza, C. 2003. Changes in carbohydrate metabolism in coconut palms infected with the lethal yellowing phytoplasma. Phytopathology 93:976-981.

Murchie, E. H., and Lawson, T. 2013. Chlorophyll fluorescence analysis: A guide to good practice and understanding some new applications. J. Exp. Bot. 64:3983-3998.

Musetti, R., Pagliari, L., Buxa, S. V., Degola, F., Marco, F. D., Loschi, A., and van Bel, A. J. 2016. OHMS**: Phytoplasmas dictate changes in sieveelement ultrastructure to accommodate their requirements for nutrition, multiplication and translocation. Plant Signal. Behav. 11:e1138191.

Ouchemoukh, S., Schweitzer, P., Bey, M. B., Djoudad-Kadji, H., and Louaileche, H. 2010. HPLC sugar profiles of Algerian honeys. Food Chem. 121:561-568.

Pagliari, L., Martini, M., Loschi, A., and Musetti, R. 2016. Looking inside phytoplasma-infected sieve elements: A combined microscopy approach using Arabidopsis thaliana as a model plant. Micron 89:87-97.

Parry, M. A., Andralojc, P., Khan, S., Lea, P. J., and Keys, A. J. 2002. Rubisco activity: Effects of drought stress. Ann. Bot. (Lond.) 89:833-839.

Porter, K. G., and Feig, Y. S. 1980. The use of DAPI for identifying and counting aquatic microflora. Limnol. Oceanogr. 25:943-948.

Reinero, A., and Beachy, R. N. 1989. Reduced photosystem II activity and accumulation of viral coat protein in chloroplasts of leaves infected with tobacco mosaic virus. Plant Physiol. 89:111-116.

Richardson, A. D., Duigan, S. P., and Berlyn, G. P. 2002. An evaluation of noninvasive methods to estimate foliar chlorophyll content. New Phytol. 153:185-194.
Roháček, K., and Barták, M. 1999. Technique of the modulated chlorophyll fluorescence: Basic concepts, useful parameters, and some applications. Photosynthetica 37:339-363.

Rudzińska-Langwald, A., and Kamińska, M. 2001. Ultrastructural changes in aster yellows phytoplasma affected Limonium sinuatum Mill. plants. I. Pathology of conducting tissues. Acta Soc. Bot. Pol. 70:173-180.

Santi, S., De Marco, F., Polizzotto, R., Grisan, S., and Musetti, R. 2013. Recovery from stolbur disease in grapevine involves changes in sugar transport and metabolism. Front. Plant Sci. 4:171-182.

Siddique, A. B. M., Guthrie, J. N., Walsh, K. B., White, D. T., and Scott, P. T. 1998. Histopathology and within-plant distribution of the phytoplasma associated with Australian papaya dieback. Plant Dis. 82:1112-1120.

Sinclair, W. A., Griffiths, H. M., and Whitlow, T. H. 1997. Comparisons of tolerance of ash yellows phytoplasmas in Fraxinus species and rootstockscion combinations. Plant Dis. 81:395-398.

Strauss, E. 2009. Phytoplasma research begins to bloom. Science 325 : 388-390.

Su, Y. T., Chen, J. C., and Lin, C. P. 2011. Phytoplasma-induced floral abnormalities in Catharanthus roseus are associated with phytoplasma accumulation and transcript repression of floral organ identity genes. Mol. Plant-Microbe Interact. 24:1502-1512.

Tan, P. Y., and Whitlow, T. 2001. Physiological responses of Catharanthus roseus (periwinkle) to ash yellows phytoplasmal infection. New Phytol. 150:757-769.

Tan, Y., Wei, H. R., Wang, J. W., Zong, X. J., Zhu, D. Z., and Liu, Q. Z. 2015. Phytoplasmas change the source-sink relationship of field-grown sweet cherry by disturbing leaf function. Physiol. Mol. Plant Pathol. 92:22-27.

Wu, Z. H., Yang, C. W., and Yang, M. Y. 2014. Photosynthesis, photosystem II efficiency, amino acid metabolism and ion distribution in rice (Oryza sativa L.) in response to alkaline stress. Photosynthetica 52:157-160.

Yuan, Z. 2014. The response of disease resistance-related genes in Chinese jujube (Ziziphus jujuba Mill.) under phytoplasma stress. Agricultural University of Hebei, China. 